\title{
Isolasi Senyawa Flavonoid Pada Biji Pinang Yaki (Areca vestiaria Giseke)
}

\author{
Cindy C. Satoloma*, Max R. J. Runtuwenea, Jemmy Abidjulua \\ aJurusan Kimia, FMIPA, Unsrat, Manado
}

\section{KATA K U N C I}

Flavonoid
Pinang Yaki

Afzelekin

\begin{abstract}
A B S T R A K
Pinang Yaki (Areca vestiaria Giseke) adalah tanaman endemik Sulawesi Utara yang berkhasiat untuk mengobati berbagai penyakit. Penelitian sebelumnya menyatakan bahwa biji dan kulit Pinang Yaki mengandung flavonoid (Samosir et al., 2012; Mamonto et al., 2014). Sekarang akan dilaporkan Isolasi Senyawa Flavonoid dari biji Pinang Yaki. Metoda yang dilakukan sebagai berikut: Ekstrak metanol difraksinasi dengan $n$-heksan, etil asetat dan air. Fraksi etil asetat dimurnikan dengan metode Kromatografi Lapis Tipis Kresgel $\mathrm{G}_{60} \mathrm{~F}_{254}$ dan Kromatografi Kolom dengan berbagai pelarut, setiap pemisahan dipandu dengan $\mathrm{AlCl}_{3} \quad 5 \%$ dalam etanol yang menampakan warna khas dari flavonoid. Isolat murni yang didapatkan selanjutnya dikarakterisasi dengan menggunakan metode spektroskopi UV dan H-NMR. Isolat murni yang diperoleh diduga adalah Afzelekin.
\end{abstract}

\begin{tabular}{l} 
K E Y W O R D S \\
\hline Pinang Yaki \\
Flavonoid \\
Afzelechin
\end{tabular}

TERSEDIA ONLINE

10 Februari 2015

\begin{abstract}
A B S T R A C T
Pinang Yaki (Areca vestiaria Giseke) is a endemic plant of North sulawesi that efficacious for various disease treatment. Same research reported that Pinang Yaki seed and skin seed contain Flavonoid compound (Samosir et al., 2012; Mamonto et al., 2014). This research reported isolation of Flavonoid compound from Pinang Yaki seed, The methods is: methanol ekstract fractionating with $n$-hexane, ethyl acetate dan aquades. Ethyl acetate fraction was purified by Thin Layer Chromatography Kresgel $\mathrm{G}_{60} \mathrm{~F}_{254}$ method and Column Chromatography with various solvent, every separation guided by $5 \% \mathrm{AlCl}_{3}$ in ethanol which reveals the typical colour of Flavonoid compound. After that, the obtained pure isolates was characterized by various UV-Spectroscopy and H-NMR methods. The structure of isolate compound predicted as Afzelechin..
\end{abstract}

\section{Pendahuluan}

Senyawa flavonoid merupakan salah satu senyawa fenolik yang di alam memiliki potensial sebagai antioksidan dan mempunyai bioaktifitas sebagai obat (Rohyami, 2009). Menurut Suryanto (2012) menyatakan bahwa biji buah pinang mengandung senyawa-senyawa fenolik dan mempunyai aktivitas sebagai penangkal radikal bebas.

Samosir et al. (2012) mengatakan kandungan total flavonoid yang terkandung pada ekstrak biji
Pinang Yaki segar sebanyak 7,573 mg/kg. Total flavonoid ekstrak metanol kulit biji Pinang Yaki dari metode sokletasi didapatkan sebanyak 2,56 mg/kg (Mamonto et al., 2014). Sekarang akan dilaporkan isolasi flavonoid dari biji buah Pinang Yaki (Areca vestiaria Giseke).

\section{Metode}

\subsection{Material}

Alat yang digunakan dalam penelitian, plat kromatografi lapis tipis (KLT) Kieselgel $60 \quad$ GF $_{254}$

*Corresponding author: Jurusan Kimia FMIPA UNSRAT, Jl. Kampus Unsrat, Manado, Indonesia 95115; Email address: cindysatolom@yahoo.com Published by FMIPA UNSRAT (2015) 
0,25 mm (Merck), plat oktadesilsilan (ODS) (Merck), spektrofotometer Shimadzu UV-160A, dan JOEL JNM-FX500. Bahan yang digunakan adalah sampel biji buah Pinang Yaki, berbagai pelarut, silika gel 60 for colomn chromathography.

\subsection{Preparasi}

Buah Pinang Yaki dipisahkan kulit buah, daging buah dan biji buah. Bagian biji dikering anginkan, setelah kering dipisahkan dari kulit bijinya. Biji kemudian dikeringkan lagi menggunakan oven bersuhu $40^{\circ} \mathrm{C}$, sehingga diperoleh kadar air kurang dari $10 \%$. Sampel biji yang telah kering dihaluskan sehingga diperoleh ukuran 65 mesh.

\subsection{Ekstraksi dan Fraksinasi}

Ekstraksi dilakukan menurut metode Rohyami (2009) yang telah dimodifikasi. Sebanyak $900 \mathrm{~g}$ serbuk biji buah dimaserasi menggunakan pelarut $n$ heksana $1000 \mathrm{~mL}$ selama 1×24 jam. Residu dimaserasi kembali dengan menggunakan pelarut metanol $80 \%$ selama $3 \times 24$ jam. Filtrat yang diperoleh digabung dan diuapkan sehingga diperoleh ekstrak kental, kemudian dipanaskan dalam oven dengan suhu $40{ }^{\circ} \mathrm{C}$ selama 24 jam sehingga didapat ekstrak kering.

Proses fraksinasi dilakukan dengan cara partisi menggunakan pelarut $n$-heksana, etil asetat, air. Sebanyak 73,8 g ekstrak kering hasil proses maserasi dilarutkan dalam $100 \mathrm{~mL}$ air. Larutan selanjutnya dipartisi dengan menambahkan $100 \mathrm{~mL}$ n-heksana.

Lapisan air sisa dari proses partisi $n$-heksana kemudian dipartisi lebih lanjut dengan etil asetat, sehingga diperoleh fraksi etilasetat dan fraksi air..

\subsection{Identifikasi Total Flavonoid}

Kandungan total flavonoid ekstrak biji pinang yaki ditentukan menurut metode Meda et al (2005).. Kandungan total flavonoid dinyatakan sebagai $\mathrm{mg}$ ekivalen kuersetin/kg ekstrak.

\subsection{Isolasi Senyawa Flavonoid}

Isolasi dan Pemurnian dilakukan menurut Kurniati (2010) yang telah dimodifikasi. Sebanyak 8,25 g dari fraksi etil asetat biji Pinang Yaki di kromatografi kolom, dengan fasa diam silika gel 60 $\mathrm{GF}_{254}$ dan fasa gerak yaitu $n$-heksana : etil asetat. Tiap fraksi yang dihasilkan dilakukan KLT, dilihat noda yang ada dengan lampu UV pada panjang gelombang $254 \mathrm{~nm}$ dan $365 \mathrm{~nm}$. $\mathrm{AlCl}_{3}$ 5\% untuk mengetahui ada/tidaknya senyawa flavonoidnya. Setiap fraksi yang memiliki pola noda dan nilai Rf yang sama digabung. Kemudian di Re-kromatografi kolom dengan fasa diam silika gel $60 \mathrm{GF}_{254}$ dan fasa gerak eluen yaitu $n$-heksana : etil asetat. Uji Kromatografi Lapis Tipis (KLT) tiap fraksi yang dihasilkan, puncak noda dibaca menggunakan lampu UV 254 dan $365 \mathrm{~nm}$. Penyemprotan $\mathrm{AlCl}_{3}$ 5\% dilakukan untuk mengetahui ada/tidaknya senyawa flavonoid.. Setiap fraksi yang memiliki pola noda dan Rf yang sam digabung. Kemudian dire-kromatografi kolom dengan fasa diam sikia gel $\mathrm{GF}_{254}$ dan fasa gerak yaitu n-heksana : etil asetat. Tiap fraksi yang sama disemprot $\mathrm{AlCl}_{3}$ 5\%. Fraksi yang teridentifikasi mengandung flavonoid dilakukan kromatografi kolom dengan fasa terbalik ODS RP-18 dan fasa gerak $\mathrm{H}_{2} \mathrm{O}$ : $\mathrm{MeOH}$. Tiap fraksi yang dihasilkan diuji $\mathrm{KLT}$ dan kemudian disemprot dengan $\mathrm{AlCl}_{3}$ 5\%, $\mathrm{H}_{2} \mathrm{SO}_{4}$ 10\%. Penyemprotan dengan $\mathrm{H}_{2} \mathrm{SO}_{4}$ dimaksudkan untuk melihat kemurnian isolat yang dihasilkan (isolat murni).

Isolat murni yang diperoleh kemudian diidentifikasi strukturnya dengan menggunakan spektrofotometer Ultra Violet (UV), dan Proton Resonansi Inti Magnet (H-NMR).

\section{Hasil dan Pembahasan}

\subsection{Hasil Penentuan Total Flavonoid}

Total flavonoid masing-masing ekstrak dan fraksi dipaparkan pada Gambar 1. Kandungan total flavonoid dari EM dan EPEA adalah yang paling tinggi dibanding ekstrak yang lain. Menurut Markham (1988). Flavonoid aglikon seperti isoflavon, flavanon dan flavon serta flavonol yang termetoksilasi cenderung lebih larut dalam pelarut yang semi polar seperti eter, kloroform, etil asetat dan $n$-butanol, sedangkan flavonoid glikosida lebih larut dalam pelarut yang lebih polar seperti air. Untuk pelarut $n$-heksana yang bersifat non polar tidak terlalu efektif untuk melarutkan flavonoid. Jadi dari hasil ini dapat menunjukkan bahwa dalam ekstrak partisi etil asetat banyak mengandung senyawa flavonoid aglikon atau flavonoid yang tidak terikat dengan gula.

Flavonoid adalah senyawa yang memiliki aktivitas sebagai antioksidan yang bertindak sebagai penangkal radikal bebas untuk itu perlu diketahui kandungan total flavonoid dalam suatu sampel. Struktur dasar flavonoid pada cincin A membentuk senyawa kompleks dengan $\mathrm{Al}^{3+}$ pada gugus hidroksi yang dapat menghasilkan warna kuning, keton dicincin $\mathrm{C}$ yang bsertetangga dan pada orto-dihidroksi dicincin B (Meda et al., 2005). Kandungan total flavonoid dinyatakan sebagai mg kuersetin/L. 


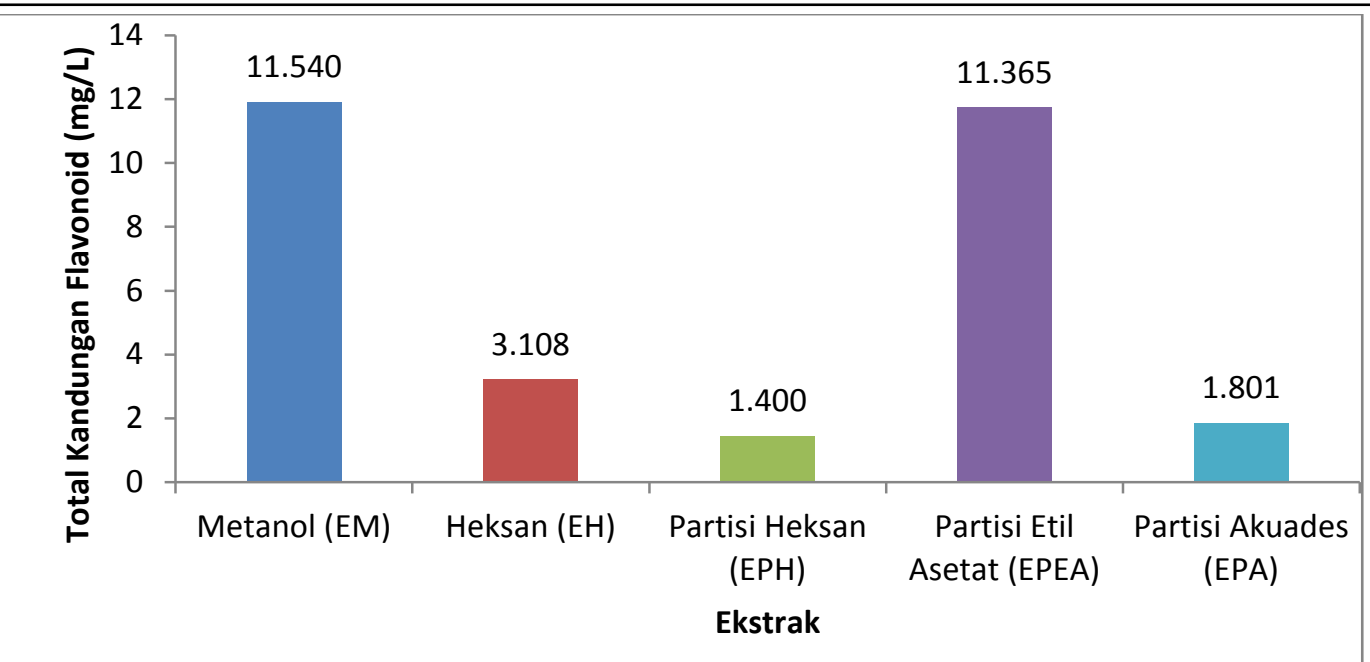

Gambar 1. Diagram Flavonoid dari ekstrak metanol (EM), ekstrak $n$-heksana (EH), ekstrak partisi $n$ heksana (EPH), ekstrak partisi etil asetat (EPEA), dan ekstrak partisi akuades (EPA)

\subsection{Pemisahan dan Pemurnian}

Sebanyak $8,252 \mathrm{~g}$ fraksi etil asetat dimurnikan menurut Kurniati (2010). Fraksi-fraksi hasil kromatografi kolom, dilakukan analisis menggunakan metode KLT dengan fasa diam silika gel $\mathrm{G}_{60} \mathrm{~F}_{254}$ dan eluen $n$-heksana : etil asetat. Hasil analisis fraksi-fraksi dari kolom dapat dilihat pada Gambar 2.

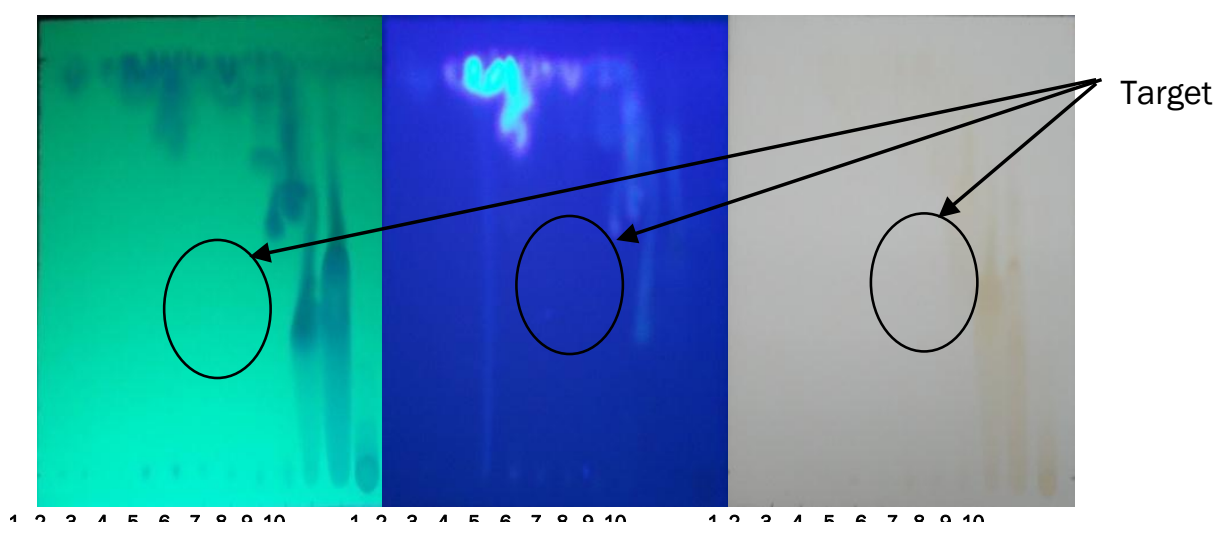

(a)

(b)

(c)

Gambar 2. Hasil kromatografi Lapis Tipis dinamakan Fraksi F-1(12) dengan fasa diam silika gel $\mathrm{G}_{60} \mathrm{~F}_{254}$ dan eluen $n$-heksana dan etil asetat (1:1) : (a) disinari UV $\lambda 254 \mathrm{~nm}$, (b) disinari UV $\lambda 365 \mathrm{~nm}$ dan (c) setelah disemprot $5 \% \mathrm{AlCl}_{3}$.dalam EtOH.

Berdasarkan hasil kolom fraksi etil asetat pada Gambar 2, diketahui bahwa fraksi F-11 memiliki masa paling banyak $9,0019 \mathrm{~g}$ dan pada saat di semprotkan $5 \% \mathrm{AlCl}_{3}$ dalam $\mathrm{EtOH}$ menampakkan noda warna kuning, hal ini, menunjukan adanya senyawa flavonoid dalam fraksi tersebut (Markham, 1988). Selanjutnya Fraksi-11 di kromatografi kolom kembali. Hasil re-kromatografi (kromatografi ke-2), kemudian dianalisis menggunakan KLT dengan fasa diam silika gel $\mathrm{G}_{60} \mathrm{~F}_{254}$ dan eluen $n$-heksana-etil asetat dapat dilihat el noda pada Gambar 3.
Gambar 3 menunjukkan bahwa fraksi F-1; 2; 3; dan 4 mempunyai pola noda yang sama sehingga dapat digabung. Selanjutnya fraksi gabungan direkromatografi kolom menggunakan fasa diam silika gel ODS (100-200 mesh) dan fasa gerak air dan metanol.

Fraksi yang dihasilkan, kemudian dianalisis menggunakan KLT dengan fasa diam silica gel ODS dan fasa gerak air - methanol. Fraksi F-5 dan F-6 mempunyai noda tunggal dan memiliki Rf yang sama $(0,64)$ (Gambar 4). 


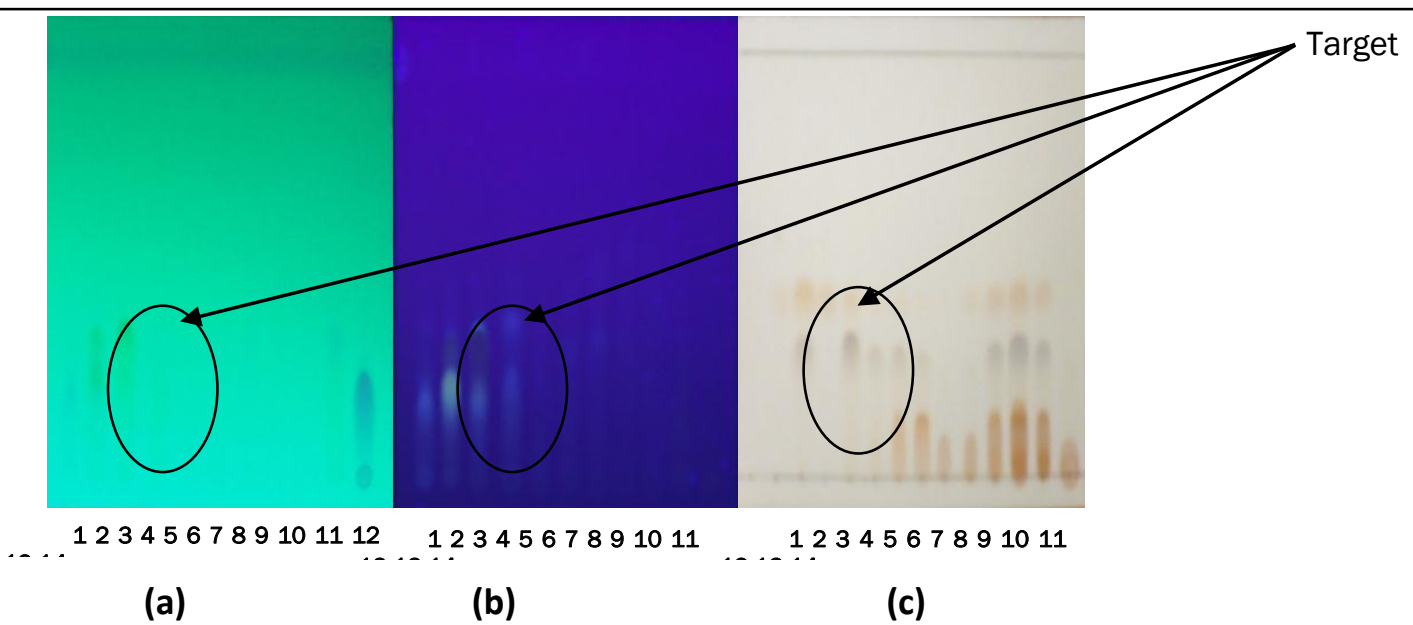

Gambar 3. Hasil kromatografi Lapis Tipis dinamakan Fraksi F-1(-14) dengan fasa diam silika gel $\mathrm{G}_{60} \mathrm{~F}_{254}$ dan eluen $n$-heksana dan etil asetat (3:7) : (a) disinari UV $\lambda 254 \mathrm{~nm}$, (b) disinari UV $\lambda 365 \mathrm{~nm}$ dan (c) setelah disemprot 5\% $\mathrm{AICl}_{3}$.dalam EtOH.

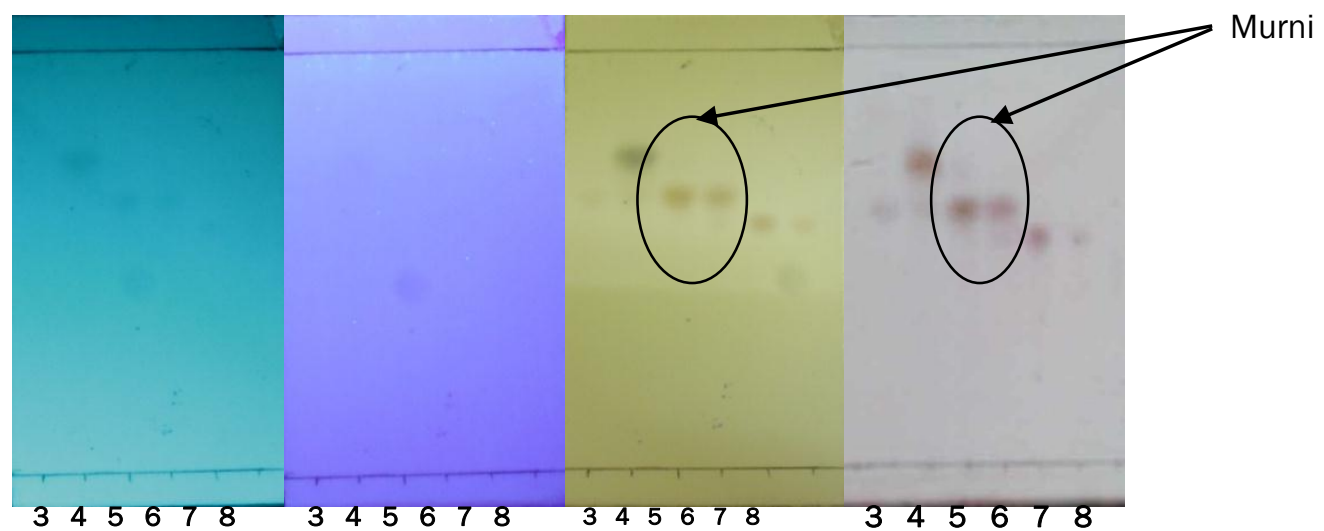

(a)

(b)

(c)

(d)

Gambar 4. Hasil kromatografi Lapis Tipis dinamakan Fraksi F-3(8) dengan fasa diam silika gel $\mathrm{G}_{60} \mathrm{~F}_{254}$ dan eluen air dan metanol (1:1) : (a) disinari UV $\lambda 254 \mathrm{~nm}$, (b) disinari UV $\lambda 365$ $\mathrm{nm}$ dan (c) setelah disemprot $5 \% \mathrm{AlCl}_{3}$.dalam EtOH dan (d) setelah disemprot $\mathrm{H}_{2} \mathrm{SO}_{4}$ $10 \%$.

Gambar 4 menunjukkan bahwa fraksi F-5 dan F-6 adalah Isolat murni, Selanjutnya dikarakterisasi menggunakan spektrometer UV-Vis dan ${ }^{1} \mathrm{H}-\mathrm{NMR}$.

\subsection{Identifikasi Spektrometer UV-Vis}

Hasil spektrum UV-Vis dapat dilihat pada Gambar 5. Puncak pertama 231,6 dan puncak kedua $275,8 \mathrm{~nm}$, kedua puncak pada Gambar 5, membuktikan bahwa senyawa tersebut yaitu flavonoid. Menurut Supratman (2010) menyatakan bahwa pada pita benzena memiliki karakteristik untuk spektra molekul aromatik dan heteroaromatik akan menunjukkan pita serapan yang lebar mengandung puncak yang banyak pada daerah ultraviolet dekat antara $230-270 \mathrm{~nm}$.

\subsection{Identifikasi dengan H-NMR}

Spektrum ${ }^{1} \mathrm{H}-\mathrm{NMR}$ isolate murni dapat dilihat pada Gambar 6. Data spektrum ${ }^{1} \mathrm{H}-\mathrm{NMR}$ senyawa isolat memperlihatkan 6 sinyal proton aromatik. Empat sinyal proton menunjukkan adanya sistem
$\mathrm{A}_{2} \mathrm{~B}_{2}$ pada $\delta_{\mathrm{H}} 7,22(2 \mathrm{H}$; d; 8,4$)$; dan $6,79(2 \mathrm{H}$; d; $8,4)$. Multiplisitas dari sinyal tersebut merupakan ciri adanya sistem $\mathrm{A}_{2} \mathrm{~B}_{2}$ dari aromatik. Hal ini diperkuat dengan adanya proton $\delta_{H} 7,22$ dan $\delta_{H}$ 6,79 yang mempunyai coupling constant sebesar $8,4 \mathrm{~Hz}$. Tetapan ini menandakan bahwa proton $\delta_{H} 7,22$ berjodoh dengan proton $\delta_{H} 6,79$, sehingga posisi dari keempat proton tersebut pada posisi orto dalam satu cincin aromatik. Sedangkan nilai $J=1,9$ $\mathrm{Hz}$ pada proton $\delta_{н} 5,93$ dan $5,84 \mathrm{ppm}$ menunjukkan bahwa kedua proton tersebut saling berposisi meta pada cincin aromatik. Adanya sinyal multiplet yang $\delta_{H} 4,58$ ppm cenderung teroksigenasi; $\delta_{H} 4,60$ ppm memiliki proton yang terkonjugasi dan ada dua sinyal proton dengan nilai $J=16,2 \mathrm{~Hz}$ pada proton $\delta_{H} 2,90 \mathrm{ppm}$ dan proton $\delta_{\mathrm{H}} 2,53 \mathrm{ppm}$ menunjukkan bahwa kedua proton tersebut merupakan proton geminal pada posisi trans. 


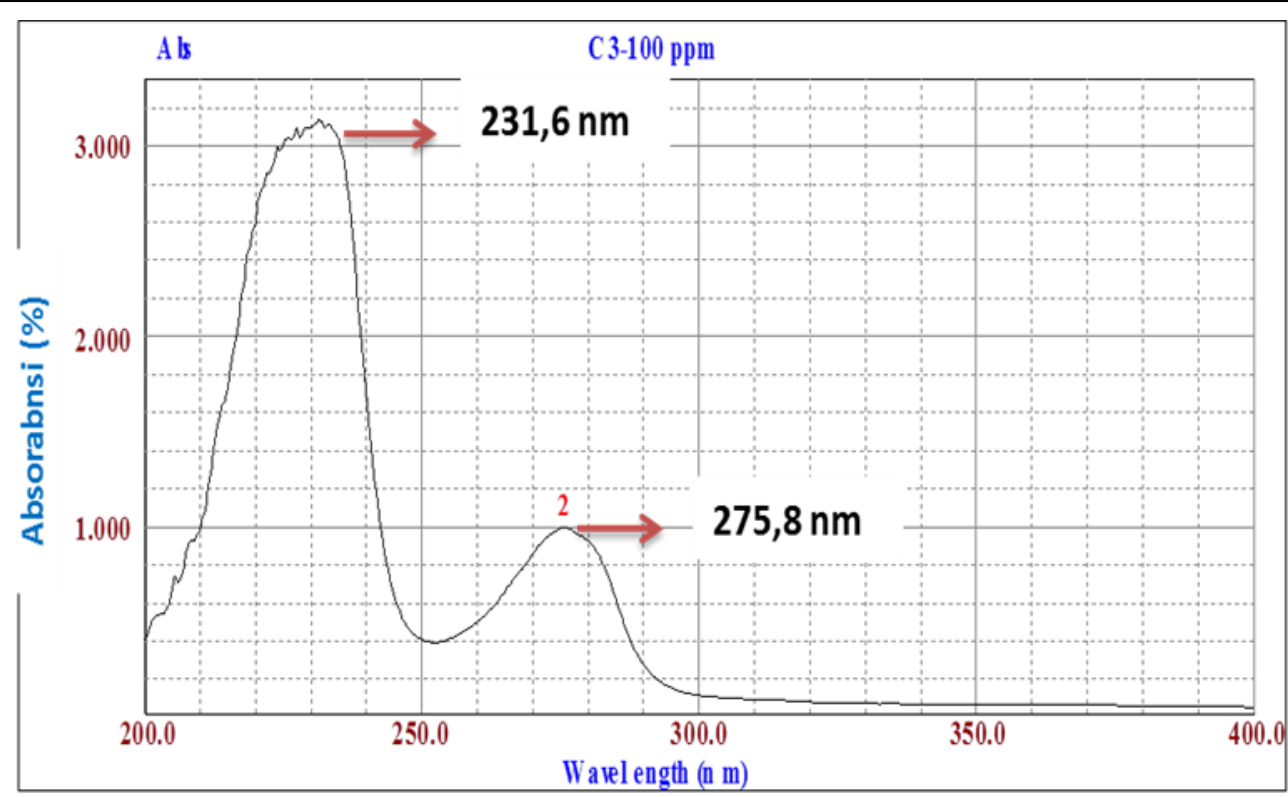

Gambar 5. Hasil spektrum UV-Vis senyawa isolat yang memiliki panjang golombang pada puncak pertama yaitu 231,6 dan puncak kedua $275,8 \mathrm{~nm}$.

Data ${ }^{1} \mathrm{H}-\mathrm{NMR}$ yang diperoleh dibandingkan dengan data 1H-NMR senyawa Afzelekin (Saraswahty dan Vidhya, 2012) adalah sama dapat
(Tabel 1). Dengan demikian isolate murni yang diperoleh diduga adalah Afzelekin suatu senyawa flavanoid.

Tabel 1. Data ${ }^{1} \mathrm{H}-\mathrm{NMR}$ Senyawa isolat dan Afzelekin

\begin{tabular}{cc}
\hline \multicolumn{2}{c}{$\delta_{H}($ Int, mult, $J=\mathrm{Hz})$} \\
\hline $\begin{array}{c}\text { Senyawa Isolat } \\
500 \mathrm{MHz}\end{array}$ & Afzelekin \\
\hline- & $400 \mathrm{MHz}$ \\
\hline $4,60(1 \mathrm{H} ; \mathrm{d})$ & $4,61(1 \mathrm{H} ; \mathrm{d})$ \\
$4,58(1 \mathrm{H} ; \mathrm{m})$ & $4,0(1 \mathrm{H} ; \mathrm{m})$ \\
$2,90(1 \mathrm{H} ; \mathrm{dd} ; 16,2$ \& 5,8) & $2,90(1 \mathrm{H} ; \mathrm{dd} ; 16,0$ \& 5,6) \\
$2,53(1 \mathrm{H} ; \mathrm{dd} ; 16,2 \& 8,4)$ & $2,52(1 \mathrm{H} ; \mathrm{dd} ; 16,0$ \& 8,4) \\
- & - \\
$5,91(1 \mathrm{H} ; \mathrm{d} ; 1,9)$ & - \\
- & $5,95(1 \mathrm{H} ; \mathrm{d} ; 2,0)$ \\
$5,82(1 \mathrm{H} ; \mathrm{dd} ; 1,9)$ & - \\
- & - \\
- & - \\
- & $7,23(1 \mathrm{H} ; \mathrm{d} ; 8,8)$ \\
$7,22(1 \mathrm{H} ; \mathrm{d} ; 8,4)$ & $6,80(1 \mathrm{H} ; \mathrm{d} ; 8,8)$ \\
$6,79(1 \mathrm{H} ; \mathrm{d} ; 8,4)$ & - \\
- & $6,80(1 \mathrm{H} ; \mathrm{d} ; 8,8)$ \\
$7,79(1 \mathrm{H} ; \mathrm{d} ; 8,4)$ & $7,23(1 \mathrm{H} ; \mathrm{d} ; 8,8)$ \\
\hline
\end{tabular}




\section{Kesimpulan}

Kandungan senyawa flavonoid yang terkandung di dalam biji Areca vestiaria Giseke yaitu senyawa flavonoid yang merupakan golongan flavan-3-ol.

\section{Daftar Pustaka}

Kurniati, D., 2010. Senyawa 4', 6, 6', 8Tetrahidroksi-3-metoksi flavon yang beraktivitas toksik dan antioksidan dari buah Merah (pandanus conoideus Lam.) [skripsi]. FMIPA UNPAD, Jatinangor.

Mamonto, I. S., M. R. J. Runtuwene., dan F. Wehantouw. 2014. Aktivitas Antioksidan Ekstrak Kulit Biji Buah Pinang Yaki (Areca Vestiaria Giseke). Jurnal IImiah Farmasi-UNSRAT. 3: 263272.

Markham, K.R. 1988. Cara mengidentifikasi flavonoida. Terjemahan Kokasih Padmawinata. ITB Press, Bandung.
Meda, A., C.E. Lamien., M. Romito., J. Milliogo., dan G.O. Nacoulina. 2005. Determination of the total phenolic, flavonoid, and proline content in Burkina fasan money, as well as their radical scavenging activity. Food Chemistry. 91: 571577

Rohyami, Y. 2009. Penentuan Kandungan Flavonoid dari Ekstrak Metanol Daging Buah Mahkota Dewa (Phaleria macrocarpa Scheff Boerl). International Standard Serial Number. 1: 1-8.

Samosir, P.A., M.R.J. Runtuwene., dan C. Gayatri. 2012. Uji Aktivitas Antioksidan dan Total Flavonoid pada Ekstrak Etanol Pinang Yaki (Areca vestiaria). Jurnal IImiah Farmasi-UNSRAT. 2: 1-6.

Supratman, U. 2010. Struktur Organik. Metode spektroskopi untuk penentuan struktur senyawa organik. Widya Padjadjaran, Bandung. 